\title{
LOGOS Article
}

\author{
Tony McSeán
}

After 30 years working in academic and research libraries, 16 of them as librarian of the British Medical Association Tony McSeán joined Elsevier in August 2004 as director of library relations. He will be working to make sure that Elsevier keeps in touch with the concerns and opinions of the library world, and develops better relations with its library customers. He has twice served as President of EAHIL and has been a Cilip councillor for ten years, and remains active in the library and information profession. The views expressed in this paper are Tony's own.

One of the Games people play in Eric Bern's book of the same name ${ }^{1}$ is "Nowadays". It is a witty evocation of the tempting fallacy that things used to be simpler/better/more relaxing in the old days - a fallacy from which none of us is immune. I've heard it applied, unusually misguidedly, to libraries. Anyone who thinks that working in a library was simpler in the old days has surely never had to perform a complex literature search without benefit of photocopier and computerised index; they absolutely have never been faced with operating a busy public library lending system using folded cardboard library tickets (machine-washed in the reader's trouser pocket) and hand-written book cards. And a glance at early $20^{\text {th }}$-century library journals will reveal the great minds of the age concerning themselves with neutralising and removing the thick layers of soot that insinuated themselves through library windows and into the fibres of the neatly shelved books and bound journals. However, as the smog has been replaced by more subtle pollutants and our desks have sprouted wires and grey boxes, some aspects of library life have indisputably become more complex and fraught. Nowhere has this been more true than in the relationship between research libraries and scholarly publishers, where things have come a long way since 1665 when the Royal Society first printed its Philosophical transactions, thereby inventing the learned journal. After centuries of more or less peaceful coexistence, an environment of rapid and fundamental technical change, restricted public finance and the sweeping away of long-established structures and relationships have replaced peaceful coexistence with a dialogue which is always lively and sometimes angry. This article traces these changes and seeks to provide some indication of whether the two former partners will grow back together or whether a separation is inevitable.

The essential elements of the modern scholarly journal were there from the very beginning: formal accounts of experimentation or observation; a system of quality assurance based on the more or less considered judgement of the author's peers; issues distributed periodically, and collected and hoarded by individual scholars and libraries. The Transactions even embodied two important publishing traditions - the learned society tradition because the Royal Society conferred its prestige on the venture, and influence of commercial publishing because for its first 100 years it was published as a private venture by the Society's secretary ${ }^{2}$. The basic functions have been remarkably constant, too: defining dispersed communities of interest, informing those scholars not in 
regular correspondence with the author, formally marking "ownership” of discoveries, conferring kudos (and occasionally obloquy) on authors, and providing a focus for university life. As international scholarship evolved, matters became more regulated, regularised and systematised but the essence as it has been for 340 years.

However, although the underpinnings and basic functions of the scholarly journal have remained unchanged, almost everything else has changed beyond recognition in the last 50 years. And with the changes have come redefinitions of the publisher/research library relationship and of the place of the library itself in the life of its users and parent institution. Two influences have had the largest impact on this process. At some point early in this period, the natural growth in the volume of scholarly communication took the body of published knowledge beyond that which the traditional methods of indexing and control could encompass. There is nothing surprising in this: the number of papers published correlates quite closely to the number of researchers at work. During the $20^{\text {th }}$ century the number of scientists has grown fairly steadily at $3 \%$ per year, with a period of faster growth following 1945, when there was a widespread feeling that science won the war and could equally well win the peace. Following on from this strategic assumption, there was substantial growth in the higher education sector as many countries prepared for a world in which the white heat of technological revolution would benefit those ready to participate.

As the annual output of learned information grew, individual researchers could no longer expect to have most of the information they required on their own shelves, and soon could no longer expect have read or even glanced at everything of relevance to their interests. Libraries became progressively unable to bring into their own stock everything their users might reasonably require to read, as budgets began to lag behind the demand they were expected to service. Researchers used their libraries more. Researchers began to cancel their personal subscriptions to journals and rely more on library copies, These cancelled subscriptions in turn reduced circulation figures and triggered a round of price increases. Some publishers may have realised how inelastic was the demand curve for important journals and made their own contribution to increased prices (followed quickly by less percipient or more PR-aware publishers). Library strategies moved steadily from independence to interdependence which libraries struggled with in meeting their users' needs using the emerging information technology of the photocopier.

Access to information about what had been published also became a problem, and library budgets were stretched further by having to subscribe to the growing number of indexing and abstracting journals. Initially these were printed and featured various more or less ingenious forms of computerised subject indexing, but this was never a long-term workable solutions and the huge printed volumes were soon supplanted by databases, searched through online links of diminishing fragility and increasing sophistication. Hugely diminishing hardware costs and fractionally easier modem access led to online searching beginning to spread beyond trained library and information professionals and be undertaken by end-users.

And then along came the web, and everything changed completely. Everyone in the academic community had access to online resources, via search facilities from decent to 
really rather good. Traditional, high-quality, vouched-for information was no longer tied to the printed page / bound volume / library shelf paradigm; on the contrary the facilities were there for $24 / 7$ searching, for systems that took you from indexes to full text with one mouse-click, for systems that could find you a journal article when all your friend could remember was a phrase or a few stray words it contained, where retrieved articles slipped automatically into bibliographic management programmes and then generated correct lists in MLA,CBE or Wotsit formats. And all this happened in your own office or home. And all this was free. And everything that was not already there on the web would be there real soon now.

These were exciting times. People who should have known better, including your author, began to froth with excitement and say wild things at conferences. The early promise of nirvana leant increased confidence to senior librarians marked the beginning of what one hopes will become a return to sanity in library/publisher relations. Some of the early promise has been fulfilled, notably in the brave and good decision of the National Library of Medicine to make Medline freely available worldwide which has contributed substantially to better medical information (and therefore better doctors and patients who get better ${ }^{3,4}$ ).

As we have moved into an era where most of us have a closer grip on the long-term realities of internet life, the relationship between library managers and scholarly publishers has become steadily more complex and time-consuming. No longer do chief librarians write the annual check to the periodicals agent and move onto other things while their staff manage the incoming paper issue. Now we have the online/paper payment conundrum, direct relations with individual publishers, access rights (who, where, when, what), security, user training (search skills, differing interfaces). And so often, overlaying it all are consortial arrangements: regional, national or sectoral deals over which can give negotiating advantages and efficiency of scale, but where an individual library manager may have limited freedom of choice and perhaps may even a little estranged from the process through which the deal was struck.

One of the difficulties, as so often with library matters, the new does not drive out the old but finds the old sitting stodgily alongside making things more complicated than seems strictly necessary. So often the old refuses to disappear, for reasons which are seldom good but invariably just good enough. In most research settings, the electronic version of a journal is now regarded at the prime version - more easily consulted and perhaps including more content, providing links to the underlying datasets or having some other enhancement impossible for the paper version. Nevertheless very, very few research libraries have moved wholesale to reliance on online journals, leaving both library and publisher to struggle providing duplicate services for decidedly unduplicate amounts of money. Opinion about the necessity of retaining paper copies is beginning its long swing. Major publishers have made serious efforts to develop perpetual archiving arrangements which will stretch to the planning horizon of the most heritage-conscious of library chiefs. Publishers and others are making concerted and expensive efforts to digitise the back-runs of journals. At the time of writing none of the major publishers has announced an intention (much less an implementation date) to abandon printing, but the first straws are in the wind. The directors of world-class research libraries are beginning to look at the implications of going 100\% electronic and pulping the backruns. The reality of major change cannot be far away, and with it should come a major simplification of library/publisher relations and one less source of tension. 
Purely within online journals there are serious technical issues to be resolved where there are no centuries of comfortable precedent to fall back upon and where the matters under discussion are so new that neither librarian nor publisher has a complete grasp of the implications. With online systems, what looks equitable, reasonable and practicable around the negotiating table can often throw up unforeseen and dynamite-laden consequences once the system is live and real users have been let loose on it consequences which need reasonable goodwill and even trust to sort out. Users expect to be able to log on to their university's online resources at any time and on any workstation in any part of the world, and translating that expectation into actuality is can be difficult.

Until now, the matters considered in this article have all concerned the threats and opportunities in the rich north - maybe being a little too concerned with the vicissitudes of the life of the wealthy. In the developing world the problems of information provision have long been more deadly and intractable: no money to buy books and journals, no access to sophisticated information services, a shortage of trained librarians, no equipment, erratic electricity and water supply. This is not new, and is not especially linked either to electronic services or publishing. There has been an honourable tradition in both library and publishing world of sharing resources and expertise. For example, the Medical Library Association's sister library programme and the UK based Partnerships in Health Information have set up links between African and UK and north American libraries that have been professionally satisfying to both sides and made a real day-to-day difference on the ground. Most of the major publishers have long donated copies of key journals to libraries with no prospect of ever being able to buy them. Although in the more distant past there was a certain tendency to pass on to poor countries the information technology before last recent initiatives such as these have emerged from a greater tendency to listen to the priorities of our colleagues on the ground.

With the web has come the prospect of leapfrog technologies for libraries in developing countries - skipping the developmental stages we have passed through in the west and going straight in with the best access to information currently available. Perhaps the best example of this is the HINARI project, which was started in 2002 with the aim of giving access to the very best health journals to practitioners and researchers in the world's hundred poorest companies. HINARI was put together jointly by the World Health Organisation, the BMJ Publishing Group and the Open Society Institute, who persuaded the world's six leading medical publishers Blackwell, Elsevier, Harcourt, Wolters Kluwer, Springer and Wiley to make available their complete range of electronic health and medical journals to the poorest countries completely free of charge in the case of the poorest and for a nominal charge for the rest, the money to be used for training and development within HINARI. The programme has now grown to over 50 scientific publishers of all types and sizes all of whom have made significant commitments to the programme's objectives. HINARI now includes all types of electronic information resources, including the full electronic journal search and access systems available throughout the world (such as Elsevier's ScienceDirect) together with databases, encyclopaedias, books, compendia, and other full-text resources. HINARI is still very much in its development stages. Technical and awareness training has been an issue, and in many cases the local infrastructure has proved unequal to the task of working with modern, high-bandwidth services. But the will to make it work remains strong on both sides and development work continues. 
The most basic parameters of the scholarly publishing industry are currently changing at an extraordinary rate - almost every week a news item appears that realigns some basic operational tenet or a new application of technology makes something slip from impressive to archaic in the time it takes to speed-read a listserv message. Libraries face a similar situation. The importance of library as place in the electronic world has already significantly diminished, and whether libraries as we know that have a long-term place in research establishments is already under serious debate. Just as there has been a trend for publishing houses to combine for strength and economies of scale, so libraries' autonomy is questioned by the growth or purchasing consortia, package deals on information resources and the increasingly common national and sectoral deals. In such an environment it would be foolish to make long-term predictions about the librarian/publisher relationship - and this author has already indicated that he has learned the hard way about the danger of visiting the wilder shores of futurology.

What does remain at least for the next few years (which is all anyone can say) is a set of common concerns and commitments. This paper started with the observation that in 340 years of scholarly journal publication little fundamental has changed. At the heart of every worthwhile scholarly journal, and of everyone concerned with its production and exploitation, lies the concept of quality of evidence. This common concern for quality now goes beyond commitment to sound peer review and takes in issues of internet literacy and search skills. Without quality the scientific method fails, and we are in the hands of mad post-modernists who think that the holocaust and the assertions of holocaust deniers are merely alternative narratives of equal validity ${ }^{5}$. Librarians and publishers are allies in the effort to ensure that scientists and others learn to distinguish the evidence of quality, peer-reviewed papers from the whittering of the merely barmy ${ }^{6}$. With some stresses and a certain amount of metaphorical flying cutlery the relationship between library and publisher, with its associated structures, continues to pass the test of time. Despite the claims of some supporters of page-charge publishing no economically and intellectually viable alternative has yet emerged from the maelstrom of possibilities that is the internet. Until it does we will all stick with the structures that work and, like any well-counselled couple, try To Make A Go Of It.

\footnotetext{
${ }^{1}$ Berne, E. Games people play: the psychology of human relationships. Penguin Books, 1964. 0140027688

${ }^{2}$ Mabe, M M. Revolution or evolution: digital myths and journal futures, sifting fact from fiction. In: Strauch, K (ed). Charleston conference proceedings 2001. Libraries Unlimited, 2003. 1591580730.

${ }^{3}$ Lindberg,D A; Siegel,E R; Rapp, B A; Wallingford, K T; Wilson, S R. Use of MEDLINE by physicians for clinical problem solving. JAMA. 269(24):3124-9, 1993 Jun 23-30.

${ }^{4}$ Haynes, R B; McKibbon, K A; Walker, C J; Ryan, N; Fitzgerald, D; Ramsden; M F. Online access to MEDLINE in clinical settings. A study of use and usefulness. Annals of Internal Medicine. 112(1):78-84, 1990 Jan 1.

${ }^{5}$ Evans, R J, In defence of history (2 ${ }^{\text {nd }}$ ed). Granta, 2001. 1862073953

${ }^{6}$ For examples of the difference consult www.quackwatch.com. For important information about soap that will wash away obesity, walk briskly to www.forhealthierlife.com .
} 